\title{
The Teaching Reform of Engineering Survey for Culturing Excellent Engineers
}

\author{
Zhengru Gan \\ Faculty of Architectural and Mapping Engineering \\ Jiangxi University of Science and Technology \\ Ganzhou, China \\ GZR1968@163.com
}

\author{
Xiaosheng Liu \\ Faculty of Architectural and Mapping Engineering \\ Jiangxi University of Science and Technology \\ Ganzhou, China
}

\begin{abstract}
The teaching reform goes through the whole teaching process and it is involved all aspects of teaching and learning. This paper has taken a beneficial exploration to the teaching of engineering survey. The back of the course reform is Jiangxi University of Science and Technology. The reform included teaching content, methods and means, practice ability, teachers' ability promotion and the course evaluation etc. Firstly, the paper analyzed situations and pointed out the problems existed in the teaching for ability target of the national "excellent" engineers of surveying and mapping. Secondly, we put forward the clear reform measures to the problems. The conclusions we can draw by the implementation is that the reform is not only feasible and has a good result. The reform around the ability target is new and original in the paper. This reform is used in other similar courses at present to culture more excellent engineers and to better serve the development of society and economy.
\end{abstract}

Keywords-ability target; culture; excellent engineer; engineering surveying; teaching reform

\section{INTRODUCTION}

For implementing the spirit of $<$ outline of the national medium and long term educational reform and development plan (2010-2020) $>$ and $<$ outline of national medium and long term talent development plan (2010-2020) >, and bitterly serving local social and economic development and industrial structure optimization and up, colleges and universities have carried out one after another the pilot works on the requirements of $<$ some opinions of the Ministry of education on the implementation of the "excellent engineer education and training program"(teach high [2011]1 number) $>$.their aims are to deepen the reform of personnel training mode, to ease employment pressure, to solve the employment problem, focus on training the excellent engineering application oriented talents with strong engineering practice ability , innovation capability and high comprehensive quality. On the background of Jiangxi University of Science and Technology, combined with the ability of the national "excellent" engineers of surveying and mapping engineering in our school, this paper analyze the problems in the teaching of engineering measurement by focusing on the cultivation of excellent engineers in surveying and mapping engineering, and put forward specific reform measures to the problems.

\section{ABILITy TARget}

According to the requirements of our university talent cultivation and orientation, the culture target of the surveying and mapping engineering is to culture the overall development senior engineering and technical personals of morality, intellectuality, physicality and ability. They master the basic principles and techniques of the spatial information of surveying and mapping about acquisition, processing, analysis, expression, application and service etc. They have a solid basic theory, generous professional knowledge, strong practical ability and good professional accomplishment. They can be competent for the works of surveying and mapping and management about the national basic surveying and mapping, urban and engineering construction surveying and mapping, survey of land and resources, investigation and exploitation of mineral resources, geological hazard monitoring and prevention, etc. They can do the development and application of Geographic Information System with strong engineering practice and scientific research ability. The ability of engineers after 5 years of training should reach the level of the high quality application engineers that reach the technical and management level of surveying and mapping engineers with the ability of design, implement, and quality supervision in surveying and mapping engineering projects, and be able to undertake the responsibility of social economy, science and technology and sustainable development. At the same time, they can lead the team to achieve success in the practice of creative surveying and mapping project. Through the implementation of the national "excellence" engineer program, the ability target of surveying and mapping engineering is reflected in the following aspects:

(1) Students should have a solid theoretical knowledge of natural science; understand the prospect of the main aspects and application of the development of modern science and technology with a good knowledge of humanities and social sciences and the basis of management science.

(2) Students should have a solid knowledge of theory and technology in the profession of surveying and mapping engineering. They include the theory, methods and techniques of spatial data acquisition, treatment, expression and utilization, and the theory, methods and techniques of surveying and mapping work in the stages of the survey and design, construction and operational monitoring. 
(3) Students should master the system professional knowledge of the project of Surveying and mapping about investigation, design, construction survey, data processing, etc. and they have certain scientific research ability on the one hand.

(4) Students should master the ability of using modern science and technology means to acquire and process information, and master the application of modern computer and information technology in surveying and mapping engineering.

(5) Students can deeply understand the law and related regulations of surveying and mapping, and familiar with technical standards and specifications of surveying and mapping engineering profession.

(6) Students should have the strong ability of the organization, management and execution in project, and the strong sense of teamwork.

(7) Students should have a strong ability to use English comprehensively. They can read English technical documents of this major proficiently and have a certain ability to communicate in English

(8) Students should be active in thinking, have consciousness and ability to develop innovative and strong self - learning ability, can keep pace with the times in learning and meet the requirements of the development of the future

\section{THE TEACHING REFORM}

For developing the target of the "excellent" engineer's ability in the surveying and mapping engineering, traditional engineering survey teaching obviously has some defects or deficiencies. Their performance is mainly in some respects as follows:

(1) It emphasizes on the system and the integrity of each subject too much, lack an overall grasp of the all curriculum system. That is not to decide the choice of the course content from the big direction. So that the knowledge of the course teaching is short of pertinence.

(2) Teaching methods and means are relatively simple.

(3) Instruments and equipment is old, not enough update and behind the engineering production. By attaching importance to theory but despising practice, the practice bases are relatively lack.

(4) Teachers are relatively weak and so on.

The result is that the training students under the traditional teaching mode are far less than the target requirements of surveying and mapping excellence engineer in comprehensive quality, especially the engineering practice ability. So it is necessary to reform the traditional teaching of engineering measurement in order to meet the ability requirements of surveying and mapping "excellent" engineer's cultivate target

\section{A. Modular teaching}

Engineering survey is a subject which involves all kinds of engineering, wide range and more content ${ }^{[1-2]}$. Today, reducing professional directory, compressing class hours, optimizing curriculum system, advocating quality education, it is not realistic to increase the hours of the course. Therefore, it is necessary to modular teaching content, to identify the ability objectives and requirements of each module and to make teaching targeted in order to choose the teaching content flexibly according to the target type of professional training, to let the students have a sense of use, to stimulating and cultivating students' autonomous learning ability. Instead of teaching students knowledge, it is better to teach students how to use knowledge. So the author thinks that the engineering surveying teaching content of excellent engineers can be roughly divided into the following modules:

(1) The principle of theory: including distance measurement, angle measurement, leveling measurement, trigonometric leveling, traverse survey, rendezvous point, basic theory of error and so on.

(2) Instrument and equipment: including conventional equipment (ruler, optical theodolite, level gauge, tablet etc), high and new technology equipment (electronic level, total station instrument, GPS etc) and special equipment (special collimator, swinger, direction instrument and gyro theodolite etc).

(3) Basic skills: observation, calculation (Including the use of the program calculator and the pocket computer and the treatment of measurement results) and drawing (including the introduction and use of surveying and mapping software).

(4) Engineering application: including the technology of surveying and mapping in the field of site formation, road and bridge, building construction, pipeline engineering, settlement deformation, equipment installation and inspection, engineering supervision, land resources and cadastral, real estate etc.

(5) Management of Surveying and mapping: measurement results, drawing data, management of instrument and equipment and Production management.

In this way, the teaching content is modularized, in other words, functional. It is convenient for teachers' teaching, not blind. It is easy for students' learning. Students know what you should learn; what is known, what is mastered, to what extent, and so on.

\section{B. The variety of teaching methods and means}

The teaching effect is good or bad. To a large extent, this depends on teaching method which is proper or not and the applied extent. Because it is not easy to pass the contents of course to students and to let the students understand and accept them in the limited 45 minutes. It depends on whether we do the homework before class, whether to play in the classroom. At the same time, it is the key to the reform of teaching content. Because the teaching content is different from the content of textbook. It is to be determined according to the teaching outline and to organize according to the teaching method. Therefore, it is necessary to use a variety of teaching methods In order to improve the quality of teaching and to optimize the teaching effect ${ }^{[3]}$. If teaching methods and means are good. It can grasp the psychology of the students; mobilize the enthusiasm of the students to listen to lectures, let the students follow the teaching thought and Inspire students' creative thinking and stimulate students' Autonomous Learning. Such teaching can make students think and get a 
multiplier effect. So the author believes that because target is clear in the surveying and mapping excellent engineers. We should break the traditional teaching mode which is mainly based on teachers. We should turn to the teaching mode which can decide on the choice of content based on the training objectives and requirements. At the same time, we can take different teaching methods and teaching means based on the content of the content. For example, guidance, inspiration, case teaching method is a kind of effective method. As the case teaching is method in which the teaching content must be closely related to the reality with running through the teaching of the actual case from beginning to end in the teaching of professional courses. Its teaching method is implemented according to the principle of the combination of teaching and students' practice. The whole process is that on the one hand the teacher says and the student does, that is, with doing while talking; On the other hand the understanding and cognition about knowledge is deepen through the links of group discussion, student evaluation, teachers' guidance etc. In other words, we can infer other things from one fact and achieve mastery through a comprehensive study of the subject by asking questions, analyzing problem and solving the problem ${ }^{[4]}$. This teaching is both combined with the actuality without vague contents and enhances teacher-student interaction by bring inspiration and discuss together as one. It can stimulate students' learning enthusiasm and thinking potential and further promote the improvement of teaching effect.

\section{Paying attention to practice}

Practical teaching is both an important link of training students' practical ability and innovative ability and an important way of improving the analysis of students, making the students understand the society, contacting with production practice, enhancing the concept of labor and realizing the goal of talent training. Through practice teaching, it not only can consolidate the students' knowledge of classroom theory also develop the students' skills of instrument operation, enhance students' independent work and the ability to solve engineering problems ${ }^{[5]}$. So the ability of engineering practice is the weather vane of the teaching effect of practice. The shortage of education funds is a common problem in Colleges and universities with the gradual transition of China's planned economy to the market economy [6]. Therefore, it is an indisputable fact that measuring instruments and equipment are old age, behind the production and the shortage. But we cannot be blindly "updated" in the face of the experimental equipment because it is not going to work to pursuit the unlimited updates by the limited input. To this end, the author thinks, on the one hand, the kind, type and grade of the instrument and equipment are "many and all" but in the number of as "small and fine" under the limited capital investment. In this way, students in school will have a more comprehensive understanding of the development of the measuring instrument by physical contact and demonstration of teacher etc. On the other hand, we can standardize practice by establishing standard campus practice base. At the same time, we can put surveying practice, in particular, the production practice and the comprehensive practice which is difficult to complete in the school to the cooperative enterprise and let students directly to participate in engineering practice by school enterprise cooperation. In this way, it is not only conducive to the development of practical teaching, but also to play the advantages of schools and enterprises to culture and train students' engineering practice ability. At the same time, we let the students to operate according to the standard by knowing the rules of measurement, to know what level of measurement should be to what extent or whether the measurement results meet the requirements; how is its precision and so on. And then it makes the school teaching practice and social engineering practice to dock seamlessly.

The evaluation of the students' practical ability in the surveying and mapping engineering profession is the whole assessment of the practice to the students by the object of the independent practice teaching (course experimental project, understanding practice, production practice and graduation design or graduation thesis and so on) and the basis of teaching objectives and implementation rules for each practice session to evaluate whether the students' practical ability training meets the requirements and to evaluate students' engineering practice ability and quality to meet the requirements of training objectives by the graduation design(thesis) and the quality of practice.

\section{Strengthening teachers}

Teaching is a process of "teaching" and "learning". First, teachers as the main body of "teaching" should change Ideas, namely from exam oriented education to quality oriented education, and set the goal direction of training ability and the concept of "learning" as the main body. As is known to all, the examination oriented education cannot make students achieve all-round development, and truly teach students according to their aptitude. But quality education not only has the unified requirements but also to maximize the development of students' personality ${ }^{[3]}$. Second, teachers should strengthen their capacity building. Because the strength of the teachers' ability directly influences the implementation of the teaching process. For this reason, on the one hand, teachers should actively participate in teaching and research activities in order to improve their professional quality and often refer to the professional literature and information In order to understand and master the research and development trends of Surveying and mapping. On the other hand, schools should actively create conditions to let teachers to accept the practice of surveying and mapping skills by school enterprise cooperation. For example, teachers go to the enterprise, construction site; the practical experienced professional and technical personnel of enterprise and engineering unit come to the school to teach or hold a lecture on the topic by inviting or employing; also teachers are arranged to the relevant schools to learn and so on. Its aim is let teachers to accept the comprehensive training of new knowledge, new technology, new instruments and practical skills. In this way, it is not only contribute to the cultivation of "double teacher" teachers but also promote the combination of theory and practice in teaching, to make the teaching of theory course run through the practice teaching organically ${ }^{[7]}$ 


\section{E. Reforming the way of assessment}

Modern science and technology is the experience essence of human beings from generation to generation. The work of surveying and mapping is often called construction ${ }^{[6]}$. Measurement is a combination of theory and practice, which is very close to the application of science ${ }^{[7]}$. In order to reflect the theory and practice of curriculum teaching and highlight the ability of each teaching module to quantify, It is necessary to strengthen the quality supervision of the curriculum and the reform of the curriculum evaluation mode

Therefore, aiming at the teaching process, our school has established the evaluation system of teaching quality of school, college and department. We organize the examination of the course in each term, arrange the teaching supervision group, department leaders and teachers to conduct spot checks and assess the teaching effect of the teacher by teaching attitude, teaching content, teaching methods, classroom order, and students' attendance rate etc in order to guarantee the normative of all teaching links.

Because the students' mastery degree of professional theory and knowledge is mainly embodied by the examination contents of the papers and students' results of the course. In order to ensure that the content of the examination paper is in line with the requirements of the course teaching objectives, the school has developed "Jiangxi University of Science and Technology examination management regulations" in which there are the detailed provisions on the examination of the proposition. At the same time, teachers must submit examination quality analysis report while they submit the list of student achievement.

In addition, in the past, the content of the assessment relies on the teaching material too much to lead students to pay attention to the theory but to light practice. So it is not fully reflect the students' mastery of the curriculum. The course results shout include the ways of exam, experiment, homework classroom performance etc, a certain percentage of each, but giving priority to exam result at the end of the course for embodying the situation of students' mastering more comprehensively. The core of the assessment way reform is to improve the weight of students' practice ability. The comparison of curriculum quantitative evaluation before the reform and after the reform is the following table 1.

TABLE I. THE QUANTITATIVE RATIO OF THE COURSE GRADE BEFORE AND AFTER IN THE REFORM

\begin{tabular}{|c|c|c|c|c|}
\hline \multirow{2}{*}{ Category } & \multicolumn{2}{|c|}{ grades at ordinary times } & \multirow{2}{*}{$\begin{array}{l}\text { Exam } \\
\text { grade }\end{array}$} & \multirow{2}{*}{$\begin{array}{c}\text { Experiment } \\
\text { grade }\end{array}$} \\
\hline & Attendance & Homework & & \\
\hline Before & $5 \%$ & $5 \%$ & $70 \%$ & $20 \%$ \\
\hline After & $10 \%$ & $10 \%$ & $50 \%$ & $30 \%$ \\
\hline
\end{tabular}

From above table 1, we can see that the curriculum evaluation after the reform strengthen classroom and promote the ratio of the ability to solve the problem and in practice. On the one hand, this is helpful to mobilize students' enthusiasm in class and interaction with teachers, seriously to do homework and to improve the ability in theory to analyze problems. On the other hand, this is not to make the student contempt practice, but to stimulate interest in experiment and passion, to promote the practice teaching, particularly to dispel the students' relied psychology under grouping situation, to exercise and enhance the students' capacity to solve practical engineering.

\section{CONCLUSION}

The results we drew that the reform is not only feasible and achieved good results by the implementation of the above teaching reform have achieved good results by the implementation of the Engineering Surveying. Its performance is in the following five aspects: (1) It avoids the blind and divorced from reality to guidance the teaching by combined with the ability target of talent training. (2) the variety of teaching methods and means promotes the teaching e course and the interaction between teachers and students. (3) It exercises and improves the engineering practice ability to pay attention to practice. (4)Strengthening teachers improves the teaching level and is adapt to the development of the times. (5) the reform the way of assessment highlights the ability and the importance of the teaching process. However, the teaching reform is a long term, complicated process. It needs that we constantly explore and practice. This reform is used in other similar courses at present to culture more excellent engineers who are suitable to social demand and to serve the development of social economy bitterly.

\section{REFERENCES}

[1] Jinsheng Ning, Junyong Chen, Deren Li, Jingnan Liu, Zuxun Zhang etc. Overview of surveying and mapping learning $[\mathrm{M}]$, Wuhan, Wuhan university press,2012(08):1-3. (In Chinese)

[2] Zhenglu Zhang, Guangyun Li, Guorong Pan etc. Engineering surveying [M], Wuhan, Wuhan university press,2014(04):1-3.. (In Chinese)

[3] Jiaxiang Zhou, Caihua Deng. The discuss of the teaching method reform in the engineering surveying of network [J], Mine survey, 2011 ( 10): 94 95. (In Chinese)

[4] Zumin Wang. The DACUM way of the surveying teaching reform on non surveying and mapping professional[J], Surveyingand Mappingof Geologyand Mineral Resources, 2000(04):37-39. (In Chinese).

[5] Wei Huang, Kun Shao. The reform and practice of the engineering surveying on professional capacity and Post demand[J], Yichun university journal, 2016(6):113-116. (In Chinese)

[6] Hongquan Xie, Haitao Jing. The discuss of the teaching method reform to the engineering surveying $[\mathrm{J}]$, Surveying and mapping engineering, 2000(09):60-62. (In Chinese)

[7] Dan Wu, Jian Gong. The preliminary discuss of the teaching reform on the engineering surveying $[\mathrm{J}]$, Liaoning province traffic college journal, 2011(04):64-65. (In Chinese) 